\title{
EFEITOS HEMOSTÁTICO E ESTRUTURAL DA ESPONJA DE CELULOSE LIOFILIZADA
}

\author{
LUIS RENATO MELLO*, FLAVIA C.NUNES MACHADO**, LEANDRO J. HAAS**, \\ VANESSA ZACCHI**, RICHARD LUZZI**, JAMES ZOSCHKE ${ }^{* *}$, RODRIGO S. RAMOS **
}

\begin{abstract}
RESUMO - Os efeitos hemostáticos da celulose oxidada (Surgicel) são bem conhecidos. Baseados na similaridade estrutural e em um possível efeito hemostático, estudamos a esponja de celulose liofilizada utilizando dois modelos experimentais. Fase I - Realizada em 12 cães, consistiu na provocação de lesão cortical com sangramento, introdução de fragmento de esponja de celulose liofilizada no interior da lesão e medida do tempo necessário para obter-se hemostasia. Os animais foram sacrificados em 7, 30 e 90 dias. A hemostasia foi obtida, em média, após 1 minuto e nenhum efeito colateral clínico foi detectado. A microscopia mostrou reação histiocitária leve aos 7 e 30 dias, com presença de pequena quantidade de células gigantes tipo corpo estranho. A reação histioplasmocitária regrediu e, aos 90 dias, a celulose estava circundada por pobre reação inflamatória. A membrana liofilizada revelou ter aspecto peculiar, representado por filamentos eosinofílicos, circundados por reação inflamatória, que diminuiu com o tempo. Somente esparsos e irregulares filamenos eosinofílicos foram percebidos aos 90 dias. Fase II - Foram introduzidos fragmentos de dimensões conhecidas de esponja de celulose, no interior do fígado de 12 ratos, que foram sacrificados em 7, 30 e 90 dias. Na autopsia, a inspeção a olho desarmado constatou, aos 30 e 90 dias, a formação de bridas peritoneais na altura do implante. Em todos os animais, especialmente aos 7 dias, a microscopia revelou intensa reação histiolinfoplasmocitária ao redor do implante. Em dois animais, aos 90 dias, detectaram-se grânulos refringentes à luz polarizada, no interior de células gigantes, demonstrando fagocitose ativa de celulose. Em conclusão, observou-se haver necessidade de modelo experimental comparativo para provar a existência de propriedades hemostáticas na esponja. Conseguiu-se, no entanto, provar a existência de reabsorção da celulose em mamíferos através de fagocitose, fato este ainda não relatado na literatura.
\end{abstract}

PALAVRAS-CHAVE: hemostasia, esponja de celulose liofilizada, córtex cerebral, fígado.

\section{Hemostatic and structural effects of lyophilized cellulose sponge}

ABSTRACT - Hemostatic effects of oxidized cellulose (Surgicel) are well known. Based on a possible similar effect of a sponge obtained after lyophilization of biosynthetic cellulose, two different experimental studies were planned. Phase I - Pieces of cellulose sponge were inserted into small provoked cortical wounds of twelve dogs. The time elapsed to obtain bloodstill after cortical damage and application of cellulose was observed in every dog, searching to detect any possible hemostatic effect of the material. The animals were sacrificed after 7, 30 and 90 days. An average time of 1 minute was elapsed until bleeding control was achieved. No clinical adverse effect was noticed. Microscopy showed histiocytic and mild foreign body reaction at 7 days, which diminished at 30 days. Almost no reaction surrounded the implant at 90 days. Lyophilized cellulose has a peculiar eosinophilic appearance, composed by thin irregular filaments which diminished their thickness with the time. At 90 days only sparse irregular cellulose filaments could be detected. Phase II - Small equal sponge fragments were inserted in the liver of twelve rats and observed 7, 30 and 90 days. At autopsy, small peritoneal adhesions were noticed at 30 and 90 days. Microscopy showed intense histioplasmocytic and foreign body reaction in all animals mainly at 7 days. In two animals, refringent intracellular cellulose particles were evident inside giant foreign body cells after 90 days. This fact evidences that cellulose can be reabsorbed by phagocytic phenomena when implanted in mammalians. A comparative group with other hemostatic material and the same method must be done to clarify the issue of hemostatic effects of this membrane.

KEY WORDS: hemostasis, biosynthetic cellulose sponge, cerebral cortex, liver.

Disciplina de Neurocirurgia, Centro de Ciências da Saúde, Universidade Regional de Blumenau: *Professor Titular de Neurocirurgia; **Estudante de Medicina. Aceite: 20-julho-1998.

Dr. Luis Renato Mello - Rua Ferdinando Schadrack 29 - 89050-370 Blumenau SC - Brasil. 
Diversas substâncias têm-se mostrado eficazes para a realização de hemostasia em córtex cerebral desde os primórdios da neurocirurgia. Em se tratando de um órgão nobre como o cérebro, o controle deve ser absoluto, e o neurocirurgião deve lançar mão de um hemostático eficiente. Dentre as principais características de um hemostático adequado podemos destacar sua capacidade de aderência à lesão com consequente formação de tampão e coagulação instantânea. Por outro lado, não deve formar aderências a estruturas adjacentes, como ossos e músculos, não prejudicando a cicatrização. Outra característica a ser lembrada é a capacidade de provocar pouca reação tecidual, diminuindo assim, os índices de complicações e de reações alérgicas. Um hemostático deve exercer sua ação mesmo quando utilizado em pequenas quantidades, tendo sua reabsorção completada em poucas semanas ${ }^{1}$.

Para hemostasia em neurocirurgia são correntemente empregados alguns produtos derivados de celulose. O propósito desta pesquisa foi verificar a viabilidade da utilização de celulose biossintética liofilizada esponjosa como hemostático. Esta película vem sendo utilizada em sua forma pura no tratamento de queimados ${ }^{2}$ e para substituição de dura-máter ${ }^{3-5}$. A forma pura de celulose, após liofilização, é submetida a processo físico obtendo-se a forma de esponja, com alto teor de reabsorção. Correlacionou-se sua similaridade estrutural com a celulose oxidada ${ }^{6}$, estabelecendo-se então a hipótese de que poderia haver, no material esponjoso a pesquisar, a mesma propriedade hemostática.

Os processos imunorreativos que desencadeiam as inflamações variam conforme a maior ou menor presença de elementos do sistema imunológico. O sistema nervoso central apresenta limitada ação imunológica por ser relativamente pobre em elementos do sistema retículo-endotelial ${ }^{7}$. Para a investigação das propriedades hemostáticas da esponja de celulose, são expostas ao cérebro de cães, fragmentos de celulose de dimensões desiguais, fornecendo inexata avaliação do grau de reabsorção do material. Frente a isso, nos propusemos também a analisar o comportamento estrutural e a reabsorção da celulose em fígado de ratos, por ser este um órgão de grande atividade imunológica.

O estudo tem, portanto, dois objetivos: verificar a ação hemostática e avaliar a reabsorção da esponja de celulose liofilizada em cérebro e em fígado de ratos.

\section{MATERIAL E MÉTODOS}

Para cada uma das etapas foram utilizados materiais e métodos diversos, que serão expostos conforme cada fase do estudo.

Fase I

A esponja de celulose foi implantada no córtex cerebral de 12 cães mestiços, previamente vacinados, divididos em três grupos. Cada grupo foi composto por 4 animais com autopsias previstas para 7, 30 e 90 dias, respectivamente, a partir da data da cirurgia.

Os animais foram operados em ambiente cirúrgico, asséptico, por indução anestésica com tionembutal, na dose de $25 \mathrm{mg} / \mathrm{Kg}$ e manutenção por inalação de halotano, a $7 \mathrm{~mL} / \mathrm{hora}$. A técnica cirúrgica constou de incisão têmporo-parietal direita em forma de ferradura, afastamento da musculatura temporal, seguida de hemostasia e craniotomia. Abriu-se a dura-máter e provocou-se lesão cortical com o aspirador, levando-se à produção de foco hemorrágico. Neste local introduziramse fragmentos de esponja de celulose de dimensões variadas. Os tempos necessários para a hemostasia foram então medidos e anotados. A seguir procedeu-se à sutura da dura-máter com Mononylon 8-0 e recolocação do fragmento ósseo. Sutura do plano muscular e pele.

Os animais foram acompanhados no pós-operatório quanto aos aspectos da ferida, estado clinico e neurológico. Após os prazos estipulados, os animais foram sacrificados com tionembutal sódico endovenoso. Injetou-se formol a $10 \%$ pelos forames ópticos e pela artéria carótida, após o clampeamento da artéria homóloga contralateral. O material permaneceu em solução de formol a $10 \%$, sendo enviado posteriormente ao Laboratório de Patologia Animal - Panlab, em Curitiba, para estudo histopatológico. Utilizaram-se colorações de hematoxilina-eosina e tricrômico de Mallory para o estudo microscópico 


\section{Fase II}

Nesta fase a esponja de celulose foi implantada no fígado de 12 ratos Wistar, com dois meses de idade, também divididos em três grupos constituídos de 4 animais cada. As autopsias foram realizadas, respectivamente, aos 7, 30 e 90 dias a partir da data da cirurgia.

A cirurgia foi realizada nas mesmas condições cirúrgicas da primeira fase e a anestesia realizada mediante injeção intraperitoneal de tionembutal, na dose de $0,25 \mathrm{mg} / \mathrm{Kg}$ de peso. A técnica cirúrgica empregada foi a mesma para as três séries, a saber: incisão abdominal mediana, interessando todos os planos com visualização do fígado. Confeccionou-se bolsa no lobo esquerdo da cápsula de Glisson, com a utilização de fio Mononylon 8-0. Procedeu-se, a seguir, incisão de aproximadamente $0,5 \mathrm{~cm}$ no centro da bolsa e introdução de fragmento de $6 \times 4 \mathrm{~mm}$ de esponja de celulose. Fechou-se, a seguir, a bolsa, certificando-se que a celulose estava em seu interior.

Os animais foram acompanhados no pós-operatório e, no prazo estipulado, sacrificados pela técnica de deslocamento cervical precedida por indução anestésica. O local da cicatriz cirúrgica foi reaberto, retirando-se o lobo hepático no qual foi introduzida a esponja de celulose. O material permaneceu em solução de formol a 10\%, sendo também encaminhado para estudo histopatológico.

\section{RESULTADOS}

Durante o período pós-operatório de ambas as fases do estudo, os animais não apresentaram sinais de infecção, reações neurológicas e/ou clínicas decorrentes do uso da esponja de celulose (Fig 1). Observou-se apenas um período de torpor, durante aproximadamente 48 horas, entre os cães, devido provavelmente à lesão cortical.

$\mathrm{Na}$ fase I, o fragmento de celulose aposto ao local de sangramento determinou hemostasia em tempo médio de um minuto. Macroscopicamente não houve alterações significativas porém, havia área de coloração escura que se aprofundava no córtex, correspondente à lesão efetuada e ao implante do material. O estudo microscópico demonstrou delgada e irregular camada de dura-máter envolvida

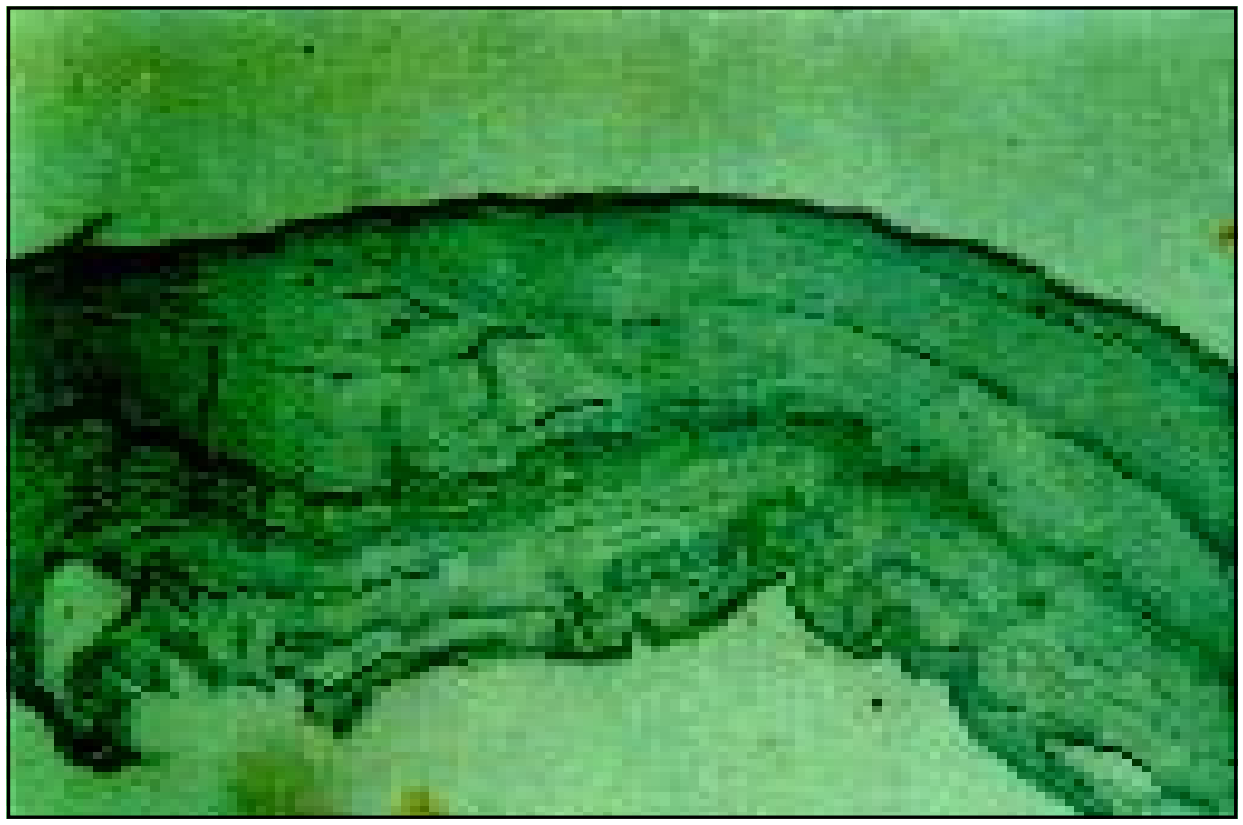

Fig 1. Aspecto da celulose liofilizada livre, incluída diretamente na parafina a $56^{\circ}$. A membrana está tumefacta, dissociada em filamentos irregulares e delgados. Aumento $4 x$. 

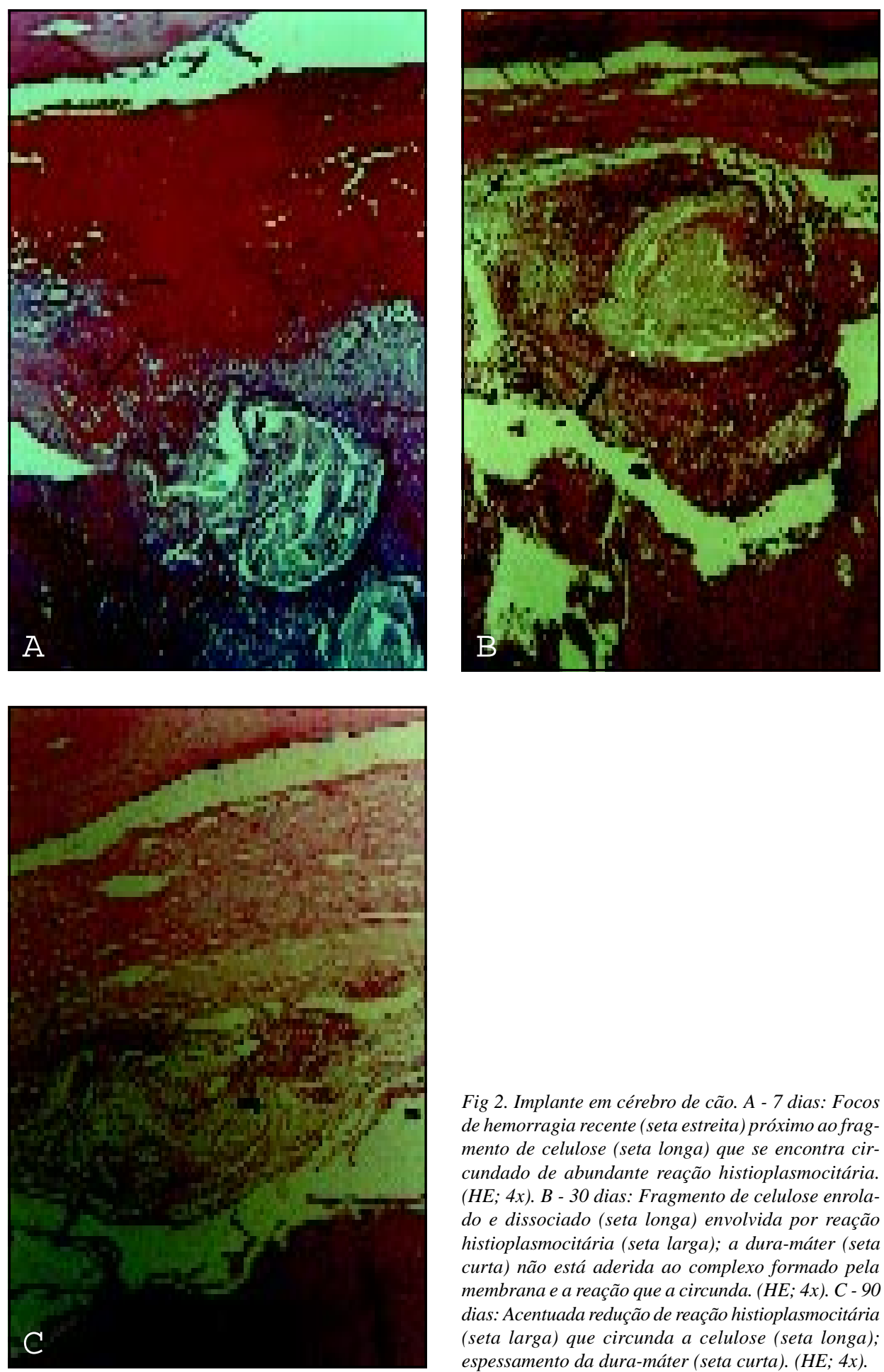

Fig 2. Implante em cérebro de cão. A - 7 dias: Focos de hemorragia recente (seta estreita) próximo ao fragmento de celulose (seta longa) que se encontra circundado de abundante reação histioplasmocitária. (HE; $4 x)$. B - 30 dias: Fragmento de celulose enrolado e dissociado (seta longa) envolvida por reação histioplasmocitária (seta larga); a dura-máter (seta curta) não está aderida ao complexo formado pela membrana e a reação que a circunda. (HE; 4x). C - 90 dias: Acentuada redução de reação histioplasmocitária (seta larga) que circunda a celulose (seta longa); espessamento da dura-máter (seta curta). (HE; 4x). 

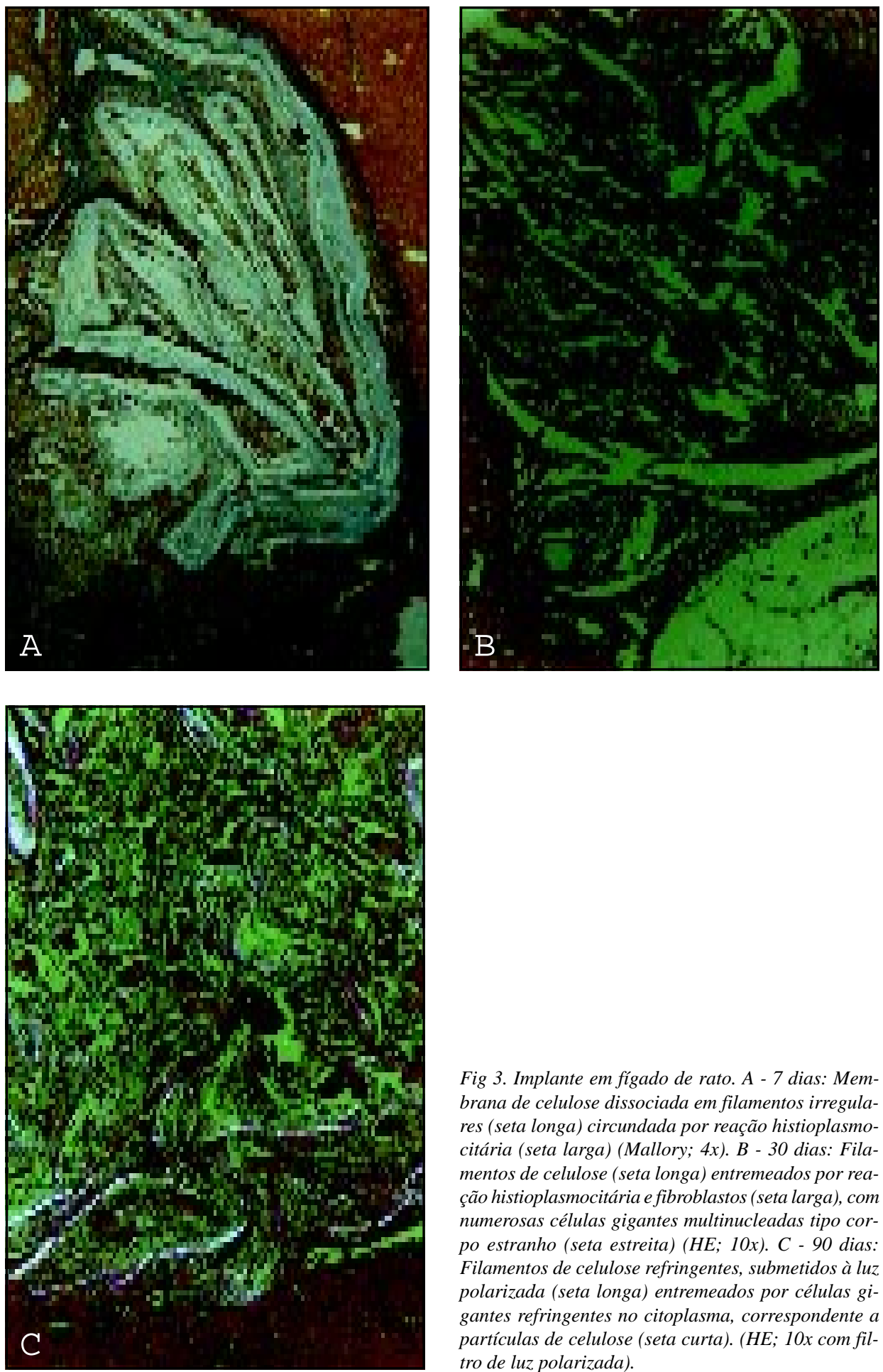

Fig 3. Implante em fígado de rato. A - 7 dias: Membrana de celulose dissociada em filamentos irregulares (seta longa) circundada por reação histioplasmocitária (seta larga) (Mallory; 4x). B - 30 dias: Filamentos de celulose (seta longa) entremeados por reação histioplasmocitária e fibroblastos (seta larga), com numerosas células gigantes multinucleadas tipo corpo estranho (seta estreita) (HE; 10x). C - 90 dias: Filamentos de celulose refringentes, submetidos à luz polarizada (seta longa) entremeados por células gigantes refringentes no citoplasma, correspondente a partículas de celulose ( seta curta). (HE; 10x com filtro de luz polarizada). 
por hemorragia, com aderência córtico-meníngea e reação histiocitária, mais intensa no grupo de 7 dias. No grupo de 30 dias já não havia mais vestígios de hemorragia e os sinais de aderência eram menores. Dentro do tecido cerebral havia filamentos eosinofílicos de celulose, de formato irregular, refringentes à luz polarizada e algumas células multi-nucleadas do tipo corpo estranho. Já no grupo de 90 dias os filamentos de celulose se tornaram esparsos e raras células gigantes foram visualizadas (Fig 2).

Na fase II, quando a esponja de celulose foi implantada em fígado de ratos, o material provocou a formação de aderências ao peritônio no local do implante, nos animais de 30 e 90 dias. Microscopicamente observou-se espessamento da cápsula de Glisson com áreas de intensa reação histioplasmocitária e neutrofílica, no grupo de 7 dias. No grupo de 30 dias havia reação inflamatória tipo corpo estranho com numerosas células gigantes multinucleadas, que diminuíram de intensidade nos animais de 90 dias. Em dois animais de 90 dias, foram evidenciadas partículas refringentes de celulose no citoplasma das células gigantes, aspectos estes não encontrados em nenhuma preparação dos animais de 7 e 30 dias (Fig 3).

\section{DISCUSSÃO}

\section{Celulose em cérebro}

O primeiro relato do uso de celulose em tecido cerebral foi feito em 1943 pôr Putnam que colocou celulose oxidada por dióxido de nitrogênio, mesclada à trombina, substituindo a dura máter. Ocorreu absorção completa da celulose em seis semanas, com mínima reação glial ${ }^{8}$. No relato patológico da mesma experiência feito por Frantz, atribuiu-se a absorção da celulose parte à dissolução pura nos álcalis orgânicos e parte à digestão por fagócitos ${ }^{6}$.

Em estudo anterior, também experimental, implantamos celulose biossintética com a intenção de analisar seus efeitos ao permanecer em contato com dura-máter, vasos e córtex cerebral, íntegros ou não. Nossos resultados mostraram que a membrana pode ser considerada um material adequado para enxerto dural, devido principalmente à ausência de aderência cortical tanto em córtex íntegro como lesado.

Preparados microscópicos demonstraram alterações estruturais da celulose pelo tecido conjuntivo ${ }^{4}$. Durante a execução prática do estudo experimental citado, vislumbrou-se a possibilidade deste material apresentar propriedades hemostáticas por ter, incidentalmente, acelerado a hemostasia após lesão de seio venoso da dura-máter de um dos cães.

Os hemostáticos mais utilizados, hoje em dia, em neurocirurgia são o Surgicel e o Oxicel. O primeiro é obtido através da oxidação da celulose, sendo que o Oxicel é a celulose oxidada regenerada. A oxidação da celulose faz com que o produto tenha um $\mathrm{pH}$ baixo, agindo como ácido orgânico. A principal diferença entre eles é que o Surgicel, conforme pesquisas do laboratório, tem sua reabsorção em 1 a 2 semanas e o Oxicel em 3 a 4. Quando expostos ao sangue, o material, que tem um $\mathrm{pH}$ de 3,5 a 4,5, se torna preto ou marrom escuro devido à formação de hematina ácida. A natureza ácida do material provavelmente produz algum efeito hemostático ${ }^{1}$. A hemostasia também depende, em parte, da marcante afinidade do ácido polianidroglicurônico pela hemoglobina e por outras proteínas do sangue. Um grande agregado hidratado é formado, que controla o sangramento simplesmente agindo como uma rolha na boca dos vasos e possibilitando a formação de coágulos ${ }^{1}$.

Microscopicamente, pode-se dizer que a celulose oxidada produz discreta reação tecidual, mínima reação glial e não produz aderência córtico-meníngea. Não provoca formação de polimorfonucleares ou células gigantes multinucleadas, somente fagócitos, geralmente circundada por depósitos de hemossiderina ${ }^{6}$. Em contato com a dura-máter, geralmente é encontrada reação inflamatória tipo corpo estranho. Pode-se constatar a capacidade bactericida da celulose oxidada devido principalmente à sua reação em meio ácido ${ }^{1}$. 
Algumas características da celulose oxidada são similares às da celulose liofilizada, tais como: discreta reação tecidual, pouca aderência córtico-meníngea e mínima reação inflamatória tipo corpo estranho.

Analisando nosso estudo, observou-se que, pelo modelo experimental montado, não foi possível verificar alterações bioquímicas do produto implantado. Observou-se, no entanto, de forma empírica, que houve aceleração do tempo de hemostasia com a aplicação do produto.

A constatação mais consistente, evidenciada nas preparações microscópicas, foi que a forma liofilizada da celulose teve estrutura e comportamento biológico diversos da celulose pura, investigada anteriormente ${ }^{3-5}$. No presente estudo os filamentos celulósicos mostraram-se irregulares, mais finos e curtos, de disposição esparsa. Aos sete dias cercaram-se de hemorragia e reação linfomononuclear modesta. Aos trinta dias desapareceu a hemorragia, acentuaram-se as reações de corpo estranho, escasseando as fibras de celulose e surgindo áreas eosinofílicas amorfas, ao lado ou substituindo as fibras de celulose. O caráter bioquímico destas áreas não foi possível determinar por métodos histológicos, correspondendo, provavelmente, ao aspecto histológico da forma liofilizada do material, nunca anteriormente descrita.

A análise destas características histológicas leva a supor que a celulose sofre degradação no organismo animal, por processo bioquímico a esclarecer. Verificou-se que o material foi parcialmente reabsorvido, faltando estimar o grau de absorção, bem como as possíveis alterações bioquímicas ligadas a seu efeito hemostático, a serem determinadas em pesquisas futuras.

\section{Celulose em tecido hepático}

A inflamação constitui-se na principal reação do organismo vivo à presença de corpo estranho. Consiste estruturalmente em exsudação de líquidos e de proteínas plasmáticas (edema) e migração de leucócitos, principalmente neutrófilos, nas primeiras horas ou dias do processo agudo. Com o passar do tempo esta reação tornar-se-á crônica, sendo menos uniforme, de maior duração, com presença de linfócitos e macrófagos, com proliferação de vasos sanguíneos e tecido conjuntivo ${ }^{7}$.

Simões e col. realizaram um estudo experimental em cães com o intuito de estudar a capacidade de hemostasia e os aspectos morfológicos da reação tecidual da película de celulose, suturada em hepatectomia parcial. Observaram imediatamente uma contenção hemostática adequada. Houve formação de aderências abundantes, principalmente com o peritônio. $\mathrm{O}$ estudo histopatológico demonstrou que a película de celulose provocou inicialmente uma exuberante reação inflamatória aguda exsudativa. Mais tardiamente, houve diminuição da extensão do processo inflamatório e aparecimento de células gigantes tipo corpo estranho e reparação fibroblástica9 ${ }^{9}$.

No ano anterior ao estudo de Simões e col., Queiroz e col. observaram esta mesma reação inflamatória com formação de granuloma de corpo estranho da película de celulose, porém ao nível do plano muscular da parede abdominal de $\operatorname{ratos}^{10}$.

No presente estudo, observou-se, nos grupos de 7 e 30 dias, intensa reação inflamatória tipo corpo estranho com presença de numerosas células gigantes multinucleadas e outros itens que caracterizam este tipo de reação. Este efeito não foi observado no cérebro quando o material foi exposto a tempos semelhantes. Já aos 90 dias esta reação inflamatória deu lugar a intensa proliferação de fibroblastos e fibras colágenas com infiltrado histiolinfoplasmocitário.

Com o passar do tempo, aos 90 dias, observou-se a presença de material refringente nas células gigantes, sugerindo reabsorção por fagocitose, fato este não observado no estudo de Simões e col. nem em outras fontes consultadas.

A justaposição dos resultados obtidos pela exposição da esponja de celulose liofilizada a áreas sangrantes de cérebro e fígado, demonstra uma possível ação hemostática deste material, a ser melhor investigada. Fornece, porém, interessantes e originais dados histológicos sobre a forma de reação e absorção da celulose liofilizada, nunca antes descrita na literatura. 


\section{REFERÊNCIAS}

1. Hurwitt ES, Henderson J, Lord GH, Gitlitz GF, Lebendiger A. A new surgical absorbable hemostatic agent: experimental and clinical evaluation. Am J Surg 1960;100:439-446.

2. Pitanguy I, Salgado F, Maracajá PF. Utilização da película de celulose (Biofill) como curativo biológico. Ver Bras Cirurg 1988;78:317-326.

3. Mello LR, Feltrin LT, Fontes PTL Neto, Abreu AR. Duraplastia com celulose biossintética: estudo experimental. Arq Bras Neurocirurg 1996;15:14-21.

4. Mello LR, Feltrin LT, Fontes PTL Neto, Abreu AR. Estudo experimental da celulose biossintética para substituição de dura-máter e proteção cerebral. J Bras Neurocirurg 1995;6:38-45.

5. Mello LR, Feltrin LT, Fontes PTL Neto, Ferraz FFP. Duroplasty with biosyntetic cellulose: an experimental study. J Neurosurg 1997;86:143-150.

6. Frantz VK. Absorbable cotton, paper and gauze (oxidized cellulose). Ann Surg 1943;118:116-126.

7. Robbins SL, Cotran RS, Kumar V. Pathologic basis of disease. 5.Ed. Philadelphia: W.B. Saunders, 1994;52-92.

8. Putnam TJ. The use of thrombin on soluble cellulose in neurosurgery: preliminary note. Ann Surg 1943;118:127.

9. Simões JC, Polonio B, Schaeffer C Neto, Pupo C, Auersvald A, Collaço LM. Aspectos morfológicos da reação tecidual da película celulósica inserida em esplenectomia parcial, hepatectomia parcial e no jejuno: estudo experimental em cães. Acta Cirurg Bras 1990;5:88-93.

10. Queiroz UF, Sivaldo RB, Simões MJ, Goldenberg S. Aspectos morfométricos da reação tecidual à película celulósica introduzida no plano muscular da parede abdominal de ratos. Acta Cirurg Bras 1989;4:144-148. 